\title{
Tin-Protoporphyrin-Mediated Disruption In Vivo of Heme Oxygenase-2 Protein Integrity and Activity in Rat Brain
}

\author{
JENNIFER A. MARK AND MAHIN D. MAINES \\ University of Rochester School of Medicine, Environmental Health Sciences Center [J.A.M.], Department of \\ Biophysics [M.D.M.], Rochester, New York 14642
}

\begin{abstract}
The ability of synthetic metalloporphyrins to suppress heme oxygenase activity and bilirubin formation has recently become of considerable clinical and experimental interest for suppression of jaundice in humans, including neonatal hyperbilirubinemia. The present investigation compares the biochemical effects of $\mathrm{Sn}-$ and $\mathrm{Zn}$ protoporphyrins on the predominant heme oxygenase isozyme present in the brain (HO-2) at activity, protein, and transcript levels and describes the ability of Sn-protoporphyrin to adversely affect this isozyme. Specifically, $6 \mathrm{~h}$ after a modest dose $(50 \mu \mathrm{mol} / \mathrm{kg}$, i.v.) of Sn-protoporphyrin, heme oxygenase activity in rat brain was nearly undetectable. In addition, as revealed by Western blot analysis, HO-2 protein level was decreased by $20 \%$ and the electrophoretic behavior of the protein in the microsomal membranes was altered. Moreover, the activity of NADPH-cytochrome $P-450$ reductase, which is required for the oxidation of heme molecule, was markedly decreased $(60 \%$ of control). Western immunoblot analysis revealed also a pronounced decrease in the reductase protein level. The inducible form of heme oxygenase, $\mathrm{HO}-1$, was not detectable by immunoblotting in brain microsomes of either control or Sn-protoporphyrin-treated animals. Northern blot analyses did not reveal decreases in the levels of the single HO-1 mRNA (1.8 kb) or the two HO2 transcripts $(1.3$ and $1.9 \mathrm{~kb})$, suggesting that Sn-protoporphyrin mediates its effects on heme oxygenase isozymes at the protein level. Zn-protoporphyrin, on the other hand, had no deleterious effect on brain parameters presently investigated. The data suggest that Sn-protoporphyrin exerts its inhibitory effects on heme oxygenase activity in the brain through multiple mechanisms involving direct effect on HO-2 protein and its cellular level, inhibiting NADPHcytochrome $\mathrm{P}-\mathbf{4 5 0}$ reductase activity, decreasing the cellular content of the reductase, as well as inhibiting heme oxygenase activity by serving as a competitive inhibitor. We suggest that $\mathrm{Zn}$-protoporphyrin may be the safer alternative if metalloporphyrins are to be used to control hyperbilirubinemia. (Pediatr Res 32: 324-329, 1992)
\end{abstract}

\section{Abbreviations}

HO-1 and HO-2, isoforms of heme oxygenase

Received February 13, 1992; accepted April 28, 1992

Correspondence and reprint requests: Mahin D. Maines, University of Rochester School of Medicine, Department of Biophysics, 601 Elmwood Ave., Rochester, NY 14642.

Supported by National Institutes of Health Grants ES03968 and ES01247 and the Graduate Training Grant ES07026. M.D.M. is the 1990 recipient of the Burroughs Wellcome Toxicology Scholarship Award.
The cleavage of heme molecule to form open tetrapyrrole biliverdin is the first and rate limiting step in the formation of bile pigments and is catalyzed by the concerted activity of the microsomal enzymes, heme oxygenase and NADPH cytochrome $\mathrm{P}-450$ reductase $(1,2)$. Heme $\mathrm{b}$ (hemin, heme, Fe-protoporphyrin-IX), which constitutes the prosthetic moiety of $b$ type cytochromes and $\mathrm{Hb}$, is the physiologic substrate of heme oxygenase $(3,4)$. Synthetic metalloporphyrins including $\mathrm{Sn}$ - and $\mathrm{Zn}$ protoporphyrins, however, are also capable of binding to the active site of the enzyme $(5,6)$ but are poor substrates and, unlike heme, do not undergo oxidative degradation by heme oxygenase $(7,8)$. In fact, because of its seemingly potent ability to decrease bile pigment formation and serum bilirubin levels by competitive inhibition of heme oxygenase, Sn-protoporphyrin has been used therapeutically to control hyperbilirubinemia in humans, including neonates (9-11).

The ability of metalloporphyrins to generate active oxygen species renders them highly reactive complexes capable of mediating the destruction of macromolecules (12-19). Not only has Sn-protoporphyrin been shown to degrade bilirubin via oxygen radical formation (16-18), but the complex plus photo-irradiation has been shown to promote lipid peroxidation both in vivo and in vitro (20). In addition, recent studies in this laboratory have demonstrated that Sn-protoporphyrin causes marked perturbations in adrenal and testicular cytochrome P-450-dependent steroidogenesis along with decreases in cytochrome P-450 levels (21). These modulations have been suggested to be a manifestation of the ability of Sn-protoporphyrin to generate free radicals (21).

There exist two isoforms of heme oxygenase, HO- 1 and $\mathrm{HO}$ $2(22,23)$, with each being a different gene product $(24,25)$. The HO-1 isozyme, which has also been designated a heat shock protein, HSP-32 (26-29), is by far the more stable form. This is exemplified by the observation that upon exposure of isozymes to $65^{\circ} \mathrm{C}$ for $10 \mathrm{~min}, 70 \%$ of $\mathrm{HO}-1$ activity is maintained, whereas HO-2 activity decreases by $80 \%$ (22). The resilient nature of HO1 could in part reflect the difference between the isozymes in their primary and secondary structures $(22-25,30)$ or alternatively may reflect a differential mode of association of the two isozymes with endoplasmic reticulum membranes. For instance, HO-2 may be localized in the microsomes in such a way that it is more accessible to cellular milieu and thus more susceptible to cytotoxic insult. In addition, the two forms differ in their regulation; the exquisite sensitivity of $\mathrm{HO}-1$ production to an array of stimuli has been extensively documented (reviewed in Ref. 4), whereas HO-2 production appears to be refractory to exogenous agents $(4,23)$. Normally, $\mathrm{HO}-2$ is the more prevalent species in most tissues; this is especially true in the brain, where HO-2 is the only form detectable by immunoblotting $(29,31-$ $33)$. It is noteworthy that the existence of HO-2 was uncovered only rather recently (22), and therefore many of the earlier studies on metalloporphyrin-mediated inhibition of bilirubin formation 
were conducted before such knowledge. The results of those studies were interpreted accordingly, as if tissues only contained HO-1.

Sn-protoporphyrin reportedly can cross the blood-brain barrier and gain entry to neuronal tissue $(34,35)$, where, as noted above, virtually all of the heme oxygenase is HO-2. Accordingly, the present investigation was undertaken to examine the effect in vivo of Sn-protoporphyrin on brain levels of HO-2 protein and its transcripts $(1.3$ and $1.9 \mathrm{~kb}$ ) as well as the heme degrading activity of this enzyme. The effect of Sn-protoporphyrin on other microsomal constituents, including NADPH cytochrome P-450 reductase, HO-1 protein, and mRNA $(1.8 \mathrm{~kb})$, was also investigated, and actions of the tin complex were compared with those of $\mathrm{Zn}$-protoporphyrin. We have uncovered deleterious effects of Sn-protoporphyrin on HO-2 protein and activity and found the effects not to be specific to the heme oxygenase isozyme, but to extend to NADPH-cytochrome P-450 reductase as well.

\section{MATERIALS AND METHODS}

Materials. Cofactors and chromatographic media were obtained from Sigma Chemical Co. (St. Louis, MO). Sn-protoporphyrin-IX dichloride and Zn-protoporphyrin-IX were obtained from Porphyrin Products (Logan, UT). Goat antirabbit IgG horseradish perioxidase conjugate and normal goat serum were purchased from Organon Teknika-Cappel (Durham, NC) and Gibco-BRL (Grand Island, NY), respectively. Nytran sheets and nitrocellulose transfer membrane, with a pore size of $0.2 \mu \mathrm{m}$, were purchased from Schleicher and Schuell Inc. (Keene, NH). All chemicals were of the highest purity commercially available. The animal experimentation described in this study was performed with the highest standards of humane care according to the guidelines set forth by the National Institutes of Health.

Animal and tissue preparation. Adult male Sprague-Dawley rats (175-225 g) were obtained from Harlan Industries (Madison, WI) and were given access to water and food ad libitum. Rats were injected with a $25.0 \mathrm{mM}$ solution of either Sn- or $\mathrm{Zn}$ protoporphyrin $(50.0 \mu \mathrm{mol} / \mathrm{kg}$, i.v. $)$ via tail vein and were killed either $6 \mathrm{~h}$ or $24 \mathrm{~h}$ later. Control animals received a comparable amount of saline. The stock $25.0 \mathrm{mM}$ metalloprotoporphyrin solutions were prepared as described previously (21). Briefly, the metalloprotoporphyrins were dissolved in a minimum volume of $0.1 \mathrm{~N} \mathrm{NaOH}$ and $95 \%$ ethanol and were thereupon diluted to $25.0 \mathrm{mM}$ by the addition of $0.9 \%$ (wt/vol) $\mathrm{NaCl}$. The $\mathrm{pH}$ was adjusted to 7.2-7.4 by the addition of $1.0 \mathrm{~N} \mathrm{NaOH}$. Manipulations involving metalloprotoporphyrins were performed under conditions of subdued lighting. Upon completion of the treatment period, the animals were decapitated and the brains were used for the preparation of subcellular fractions, or they were frozen in a dry-ice-ethanol bath and placed at $-80^{\circ} \mathrm{C}$ until used for mRNA isolation. Brains were homogenized in ten tissue volumes of $10.0 \mathrm{mM}$ Tris- $\mathrm{HCl}$ buffer, $\mathrm{pH} 7.4$, containing 0.25 $M$ sucrose, and the microsomal and mitochondrial fractions were thereupon prepared as previously described (36).

Purification of enzymes and antibody preparations. Purification of rat liver HO-1, testes HO-2, liver NADPH-cytochrome $\mathrm{P}-450$ reductase, and liver biliverdin reductase was carried out as previously described $(22,23,37$, and 38 , respectively). The $\mathrm{HO}-1, \mathrm{HO}-2$, and NADPH-cytochrome $\mathrm{P}-450$ reductase enzyme preparations were used to raise antibody in New Zealand White rabbits as previously detailed (39).

Probes, RNA preparation, and Northern blot analysis. The HO-2 probe used was the full-length (1300-bp) HO-2 cDNA purified from a rat testis cDNA library (25). A previously described (33) adaptation of the PCR technique (40) was used to generate a cDNA fragment corresponding to $\mathrm{HO}-1$ nucleotides +71 to +833 as reported by Shibahara et al. (30). HO-1, HO-2, and mouse $\alpha$-actin cDNA probes (41) were labeled by the random priming method according to the manufacturer's instructions (Random Primers DNA Labeling Kit, U.S. Biochemical
Corp., Cleveland, $\mathrm{OH})$. The probes were further purified by spin column chromatography as described by Maniatis et al. (42), using Sephadex G-50.

Total RNA was isolated from rat brain by the guanidine isothiocyanate/cesium chloride technique, as described by Chirgwin et al. (43). Poly(A) ${ }^{+}$RNA was isolated using oligo(dT)cellulose columns (44). Subsequently, $4 \mu \mathrm{g}$ of poly $(\mathrm{A})^{+}$RNA were fractionated on a denaturing formaldehyde-agarose $(1.2 \%)$ gel and transferred to Nytran (44). Prehybridization, hybridization of the appropriately labeled cDNA probe, posthybridization washes of the filters, and autoradiography on Kodak XOMATAR film at $-80^{\circ} \mathrm{C}$ were performed as previously described (33). Northern blots were quantified densitometrically using an Ultra Scan XL densitometer (Pharmacia LKB Biotechnology, Inc., Piscataway, NJ).

Assays. Microsomal heme oxygenase activity was measured in both the presence and absence of exogenous NADPH-cytochrome P-450 reductase, as detailed elsewhere (39). Purified rat liver biliverdin reductase was used to convert biliverdin to bilirubin, and the amount of bilirubin formed was determined using an extinction coefficient of $40 \mathrm{mM}^{-1} \mathrm{~cm}^{-1}$ between 470 and 530 nm (2). NADPH-cytochrome $\mathrm{P}-450$ reductase activity was estimated as described by Strobel and Dignam (45) by measuring the increase in absorbance at $550 \mathrm{~nm}$ as a result of the reduction of cytochrome $c$ in the presence of NADPH.

The protein concentration was determined by the method of Lowry et al. (46) using BSA as the protein standard.

In vitro studies. The in vitro effects of Sn-protoporphyrin on the immunochemical properties of brain microsomal HO-2 were investigated by incubating brain microsomes with Sn-protoporphyrin $\left(10 \mu \mathrm{M}\right.$ final concentration) at $37^{\circ} \mathrm{C}$ for $0,5,15$, and 45 min before electrophoresis and Western blotting.

Western blot analysis. Protein samples were fractionated by SDS-PAGE (47) in $1.5-\mathrm{mm}$ slab gels and were subsequently transferred to nitrocellulose membranes according to the method of Towbin et al. (48), using an LKB Transphor Electroblotting Cell. The method used for immunostaining has been described previously (23). Purified HO-1 $(50 \mu \mathrm{g}), \mathrm{HO}-2(150 \mu \mathrm{g})$, and NADPH-cytochrome P-450 reductase $(50 \mu \mathrm{g})$ were used as standards. Density of bands was quantified using an Ultra Scan XL densitometer. Densitometric quantifications were linear with respect to the amount of protein loaded. The Western and Northern blots displayed represent two to four determinations with one rat per determination.

Data analysis. Statistical analysis was performed using $t$ test; a value of $p \leq 0.05$ was regarded as significant. Data are presented as the mean $\pm \mathrm{SD}$.

\section{RESULTS}

The comparative effects of Sn- and Zn-protoporphyrin on brain heme oxygenase activity were investigated, and the results are depicted in Figure 1. For this experiment, rats were treated with either Sn- or $\mathrm{Zn}$-protoporphyrin $(50 \mu \mathrm{mol} / \mathrm{kg}$, i.v. $)$ and were killed $6 \mathrm{~h}$ later. As shown, Sn-protoporphyrin had a marked inhibitory effect on heme oxygenase activity, resulting in nearly negligible activity when compared with that of the controls. In contrast, in $\mathrm{Zn}$-protoporphyrin-treated rats no alteration of heme oxygenase activity in the brain was detected.

Oxidation of heme requires the concerted activity of NADPHcytochrome P-450 reductase along with heme oxygenase isozymes; therefore, the possibility that the observed decrease in heme oxygenase activity by Sn-protoporphyrin treatment was caused by compromised NADPH-cytochrome P-450 reductase activity in the brain was explored. This possibility was investigated by measuring the heme oxygenase activity in the presence of exogenously supplemented reductase as well as measuring the reductase activity in brain microsomal fractions obtained from rats treated with Sn-protoporphyrin for $6 \mathrm{~h}$. For comparison, the study also included rats treated with $\mathrm{Zn}$-protoporphyrin. The 


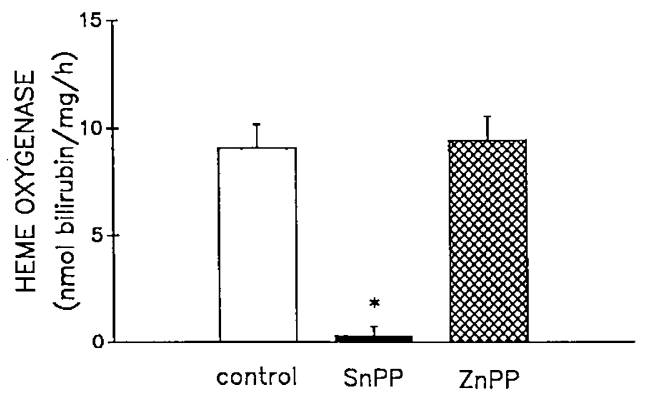

Fig. 1. Effect in vivo of Sn- or Zn-protoporphyrin treatment on rat brain heme oxygenase activity. Male Sprague-Dawley (175- to 225-g) rats were treated with either $\mathrm{Sn}$-protoporphyrin $(S n P P)$ or $\mathrm{Zn}$-protoporphyrin $(Z n P P)(50.0 \mu \mathrm{mol} / \mathrm{kg}$, i.v. $)$ and killed $6 \mathrm{~h}$ later. The brain microsomal fractions were prepared and used for measurement of heme oxygenase activity. Experimental details are provided in Materials and Methods. The data are presented as mean \pm SD of four determinations; one rat was used for each determination. An asterisk denotes $p \leq 0.05$ when compared with the control group.

Table 1. Effect in vivo of Sn- and Zn-protoporphyrin on brain microsomal NADPH-cytochrome $P-450$ reductase activity and consequence of supplementation of heme oxygenase system with reductase*

\begin{tabular}{lcc}
\hline & $\begin{array}{c}\text { NADPH-cytochrome } \\
\text { P-450 reductase } \\
\text { Treatment }\end{array}$ & $\begin{array}{c}\text { Heme oxygenase } \\
\text { supplemented with } \\
\text { reductase } \\
\text { (nmol bilirubin/mg/m) } / \mathrm{m} / \mathrm{min})\end{array}$ \\
\hline Control & $17.01 \pm 3.08$ & $13.10 \pm 1.89$ \\
Sn-protoporphyrin & $10.17 \pm 0.96 \dagger$ & $3.64 \pm 0.38 \dagger$ \\
Zn-protoporphyrin & $16.55 \pm 0.98$ & $12.25 \pm 0.77$ \\
\hline
\end{tabular}

* Microsomal fractions were obtained from the brains of rats treated with either $\mathrm{Sn}$ - or $\mathrm{Zn}$-protoporphyrin for $6 \mathrm{~h}$ and were thereupon used to determine the activity of NADPH-cytochrome P-450 reductase. The microsomal fractions were also used in a heme oxygenase assay system supplemented with exogenous reductase $(0.0875$ units reductase $/ 0.5 \mathrm{~mL}$ assay system, where one unit represents that amount of enzyme that catalyzes the reduction of $1 \mu \mathrm{mol}$ of cytochrome $c$ in $1 \mathrm{~min}$ at $30^{\circ} \mathrm{C}$ ). Data presented are the mean \pm SD of four determinations. Details are provided in Materials and Methods.

$\dagger p \leq 0.05$ when compared with the control group.

results are depicted in Table 1. As shown, Sn-protoporphyrin did indeed exert a deleterious effect on NADPH-cytochrome P-450 reductase activity; microsomes obtained from the brains of rats treated with $\mathrm{Sn}$-protoporphyrin displayed a $40 \%$ reduction in the reductase activity when compared with control activity. Supplementation with exogenous NADPH-cytochrome P-450 reductase of the heme oxygenase assay system containing the microsomal fraction from Sn-protoporphyrin-treated rats as the enzyme source resulted in higher activity than that noted in the absence of supplementation (Fig. 1). However, the activity remained substantially lower than that of the control. Zn-protoporphyrin exerted no significant effect on the activity of the reductase. We also examined effects of Sn-protoporphyrin treatment $24 \mathrm{~h}$ after injection; at this time the activity of heme oxygenase approached that of the control value; however, the reductase activity remained somewhat lower than that of the controls $(13.70 \pm 0.44$ versus $17.01 \pm 3.08 \mathrm{nmol} / \mathrm{mg} / \mathrm{min})$.

The possibility that the observed dissolution of brain heme oxygenase activity upon treatment with Sn-protoporphyrin did not reflect solely the inhibition of enzyme activity was investigated by examining the effect of Sn-protoporphyrin treatment on enzyme protein using Western immunoblot technique. In addition, the microsomal levels of HO-1 and NADPH-cytochrome P-450 reductase were also assessed by this technique. The results are presented in Figure 2. In these experiments, rats were treated for $6 \mathrm{~h}$ or $24 \mathrm{~h}$ with Sn-protoporphyrin. The blot
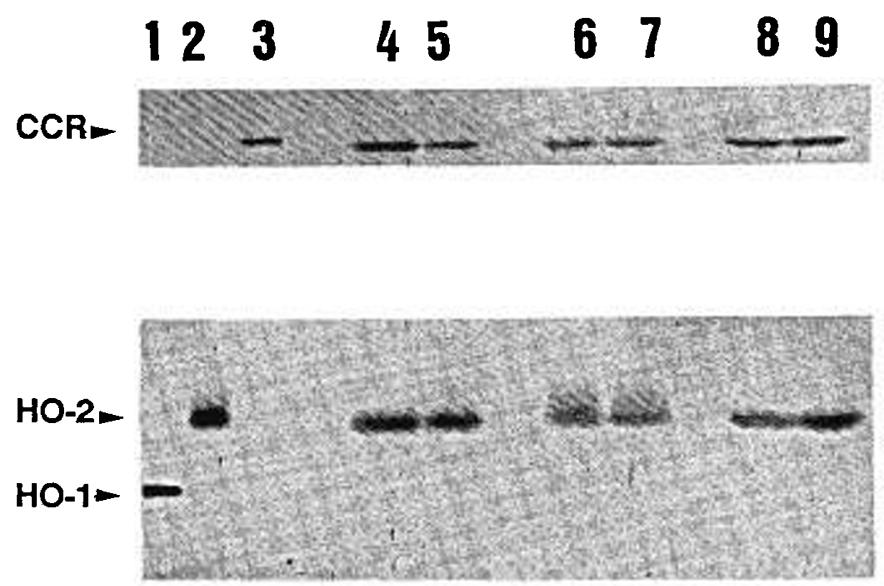

Fig. 2. Western immunoblot analysis of microsomal content of HO1, HO-2, and NADPH-cytochrome P-450 reductase in brain of Snprotoporphyrin-treated rats. Microsomal fractions were prepared from the brains of Sprague-Dawley rats treated with Sn-protoporphyrin as described in the legend to Figure 1 and killed either 6 or $24 \mathrm{~h}$ later. Western blot analysis of HO-1, HO-2, and NADPH-cytochrome P-450 reductase $(C C R)$ was carried out as described in Materials and Methods. The blot was developed using rabbit antibody preparations to rat liver HO-1, rat testes HO-2, and rat liver NADPH-cytochrome P-450 reductase. Purified preparations of $\mathrm{HO}-1, \mathrm{HO}-2$, and NADPH-cytochrome P450 reductase were used as standards. Lane 1, $50 \mathrm{ng}$ of purified HO-1; lane 2, $150 \mathrm{ng}$ of purified $\mathrm{HO}-2$; lane 3, $50 \mathrm{ng}$ of purified NADPHcytochrome P-450 reductase; lanes 4 and 5, control; lanes 6 and 7, $6 \mathrm{~h}$ Sn-protoporphyrin; and lanes 8 and 9, $24 \mathrm{~h}$ Sn-protoporphyrin. Lanes 4-9 each contained $215 \mu \mathrm{g}$ of microsomal protein.

was developed using an antibody preparation to $\mathrm{HO}-1$ (bottom panel), HO-2 (middle panel), and the reductase (top panel). As shown, HO-1 could not be visualized by Western immunoblotting (bottom panel) under control or Sn-protoporphyrin-treated conditions, an observation that is consistent with our previous reports $(28,29)$. In contrast, $\mathrm{HO}-2$ and NADPH-cytochrome P450 reductase were readily visualized. In microsomal fraction obtained from the brain of rats treated with $\mathrm{Sn}$-protoporphyrin for $6 \mathrm{~h}$ (lanes 6 and 7), both $\mathrm{HO}-2$ and the reductase were quantitatively diminished. Indeed, the detectable level of NADPH-cytochrome P-450 reductase protein was decreased by $32.7 \pm 6.8 \%(n=4)$ when compared with control levels. As also noted, both the electrophoretic behavior and the level of HO-2 in the brain microsomes from 6-h Sn-protoporphyrin-treated rats differed from those of the control or 24-h Sn-protoporphyrintreated animals; the protein appeared as a wide and diffuse band and its level was reduced by $21 \%$ when compared with the control. HO-2 and NADPH-cytochrome $\mathrm{P}-450$ reductase levels in protein samples obtained from 24-h Sn-protoporphyrintreated rats (lanes 8 and 9) were comparable to those of the controls. Treatment of rats with Zn-protoporphyrin for $6 \mathrm{~h}$ did not alter either the level or quality of $\mathrm{HO}-2$, as seen in Figure 3.

The possibility that Sn-protoporphyrin was interfering with the immunochemical properties of $\mathrm{HO}-2$ and rendering it less readily detectable by immunoblotting was investigated, and the results are shown in Figure 4. Before fractionation and immunoblotting, Sn-protoporphyrin (10 $\mu \mathrm{M}$ final concentration) was incubated with $150-\mu \mathrm{g}$ protein samples of control brain microsomes at $37^{\circ} \mathrm{C}$ for $0,5,15$, and $45 \mathrm{~min}$ (lanes $2-5$, respectively). As shown, the metalloporphyrin did not appear to alter the immunochemical properties of $\mathrm{HO}-2$.

In the subsequent experiment, we examined the possibility that Sn-protoporphyrin may exert deleterious effects on $\mathrm{HO}-2$ transcripts ( 1.3 and $1.9 \mathrm{~kb}$ ) in the brain, which were subsequently reflected in decreased protein levels. For comparison, Northern blot analysis of brain HO-1 mRNA (1.8 kb) was also carried out. As shown in Figure 5, Northern blot analysis revealed that no 


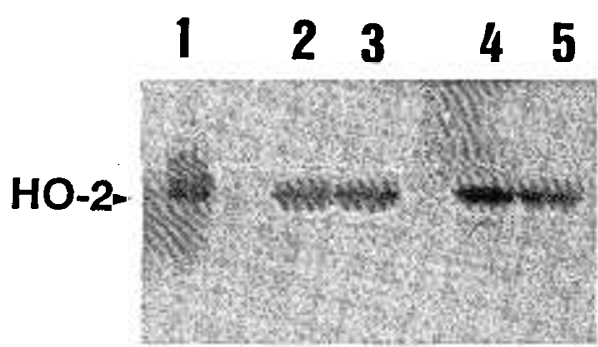

Fig. 3. Effect in vivo of $\mathrm{Zn}$-protoporphyrin treatment on rat brain microsomal HO-2 as visualized by Western immunoblot analysis. Microsomal fractions from the brains of rats treated with $\mathrm{Zn}$-protoporphyrin $(50 \mu \mathrm{mol} / \mathrm{kg}$, i.v. $)$ and killed $6 \mathrm{~h}$ later were obtained as detailed in the text. HO-2 was visualized by Western immunoblot analysis as described in Materials and Methods. The blots were developed using rabbit antibody to rat testes HO-2. Lane 1, $150 \mathrm{ng}$ purified HO-2; lanes 2 and 3, control; and lanes 4 and 5, $6 \mathrm{~h}$ Zn-protoporphyrin. Lanes 2-5 each contained $150 \mu \mathrm{g}$ of microsomal protein.

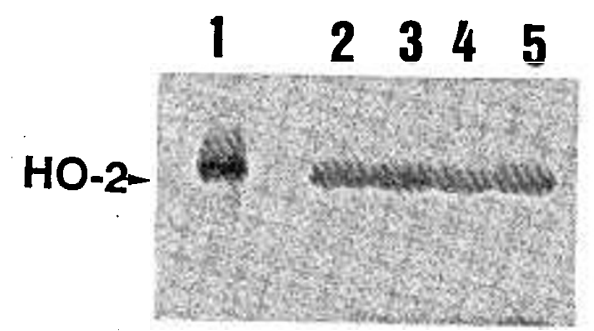

Fig. 4. Effect in vitro of Sn-protoporphyrin on the immunochemical properties of $\mathrm{HO}-2$ as assessed by Western immunoblotting. One hundred fifty- $\mu \mathrm{g}$ samples of control brain microsomal protein were incubated at $37^{\circ} \mathrm{C}$ with Sn-protoporphyrin $(10 \mu \mathrm{M}$ final concentration) for $0,5,15$, and $45 \mathrm{~min}$. Thereafter, the samples were used for Western immunoblot analysis. Lane 1, standard HO-2; lanes 2-5, 0, 5, 15, and $45 \mathrm{~min}$ incubation with Sn-protoporphyrin, respectively.

changes occurred in either the single HO- 1 mRNA (middle panel) or the two HO-2 mRNA levels (top panel) when poly(A) ${ }^{+}$ RNA was analyzed from rats treated $6 \mathrm{~h}$ and $24 \mathrm{~h}$ with Snprotoporphyrin (lanes 3 and 4 and 5 and 6 , respectively). Also, the ratio of the two HO-2 transcripts did not change. These findings suggest that in the brain Sn-protoporphyrin exerts its effects, for the most part, at the protein level and suggest further the possibility that regulatory mechanisms for $\mathrm{HO}-1$ and $\mathrm{HO}-2$ in the brain are refractory to the metalloporphyrin. The absence of an increase in HO-1 mRNA in brain is rather intriguing insofar that this isozyme is induced in the liver by Sn-protoporphyrin treatment (49).

\section{DISCUSSION}

Recently, the potential clinical use of Sn-protoporphyrin to suppress metabolic disorders of bilirubin metabolism such as Gilbert's syndrome in adults and postparturition hyperbilirubinemia in infants has been deemed as an attractive alternative to customary methods of treatment such as phototherapy and administration of barbiturates $(9-11)$. The promise of utility of the metalloporphyrin in clinical settings has been based on the premise that the complex is a specific competitive inhibitor of heme oxygenase and rather innocuous in nature. However, earlier inhibition studies were conducted in the absence of the knowledge of the existence of HO-2, the highly labile and noninducible form of heme oxygenase $(22,23)$. The assumption of safety finds its foundation in studies that investigated a narrow range of biotransformation activities in the kidney and liver and some hematologic parameters in experimental animals $(7,50-$ 52), wherein Sn-protoporphyrin reportedly did not appear to alter the assessed parameters to a discernible degree. In these

\section{$\begin{array}{llllll}1 & 2 & 3 & 4 & 5 & 6\end{array}$}
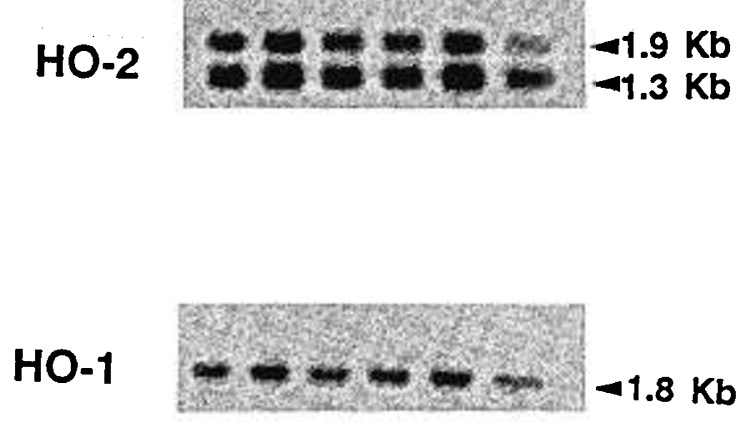

$\alpha$-actin

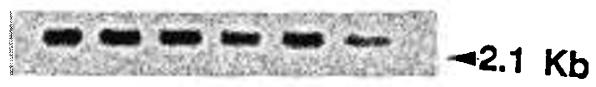

Fig. 5. Levels of HO-1 and HO-2 mRNA in brains of rats treated with Sn-protoporphyrin. Rats were treated for either 6 or $24 \mathrm{~h}$ with Snprotoporphyrin $(50 \mu \mathrm{mol} / \mathrm{kg}$, i.v. $)$. Poly $(\mathrm{A})^{+}$RNA was isolated and Northern blot analyses were performed as described in Materials and Methods. A full-length ${ }^{32}$ P-labeled HO-2 cDNA was used as the hybridization probe for $\mathrm{HO}-2 \mathrm{mRNA}$ (top panels), and a ${ }^{32} \mathrm{P}$-labeled $\mathrm{HO}-1$ cDNA fragment was used to probe for HO-1 mRNA (middle panel). The same blot was subsequently probed with $\alpha$-actin (bottom panel). Each lane contained $4 \mu \mathrm{g}$ mRNA. Filters were exposed at $-80^{\circ} \mathrm{C}$ with intensifying screen. Lanes 1 and 2, control; lanes 3 and 4, $6 \mathrm{~h} \mathrm{Sn-}$ protoporphyrin treatment; and lanes 5 and $6,24 \mathrm{~h}$ Sn-protoporphyrin treatment.

studies, in both rats and mice, acute treatment with large quantities of $\mathrm{Sn}$-protoporphyrin $(100 \mu \mathrm{mol} / \mathrm{kg} / \mathrm{d}$ for $5 \mathrm{~d})$ or long-term (8-32 wk) administration of the complex were found rather innocuous $(51,52)$.

The ability to assess the effect of the metalloporphyrin on $\mathrm{HO}$ 2 has only recently become feasible.- The present study took advantage of the recent availability of a CDNA probe (24) as well as primary antibody to $\mathrm{HO}-2$ (23) to explore the effects of $\mathrm{Sn}$ protoporphyrin treatment on this isozyme in the brain. Under normal conditions, $\mathrm{HO}-2$ accounts for nearly all heme oxygenase activity detected in the brain (28). As noted in Figure 1, the extent of inhibition of bilirubin formation in this organ was most striking, wherein the activity was nearly negligible $6 \mathrm{~h}$ after treatment. Sn-protoporphyrin has been previously reported to be detectable in the brain, albeit at low levels, $4 \mathrm{~h}$ after injection of the complex to adult rats (34). It is, however, cleared from this organ very rapidly when compared with other tissues. Indeed, Anderson et al. (34) have noted that $12 \mathrm{~h}$ after Sn-protoporphyrin injection the complex is no longer detectable in the brain, whereas its levels are maintained in other organs such as kidney and liver. The rapid clearance of the complex is consistent with the presently observed return toward normal of the activity and protein levels of HO-2 $24 \mathrm{~h}$ after Sn-protoporphyrin injection (Fig. 2). It would appear that without the direct effect of Snprotoporphyrin, normal turnover of the noninducible isozyme as well as static levels of its transcripts would permit the activity and protein levels to return to normal.

When in the brain, aside from its known competitive inhibition of heme oxygenase activity $(7,8)$, a number of other actions of Sn-protoporphyrin could account for the diminution of heme oxygenase activity. These are elaborated upon and discussed in the following. Recent studies with purified $\mathrm{HO}-1$ and $\mathrm{HO}-2$ suggest that the latter is more susceptible to inhibition by $\mathrm{Sn}$ protoporphyrin than $\mathrm{HO}-1$ (53). It follows that the brain, where virtually all heme oxygenase is $\mathrm{HO}-2$, would be predicted to be 
especially susceptible to Sn-protoporphyrin-mediated inhibition. However, considering that Sn-protoporphyrin has been shown to promote photosensitization of bilirubin as well as its degradation (16-18), the presently observed virtual depletion of measurable amounts of bilirubin in the heme oxygenase assay system containing microsomes from rats treated with $\mathrm{Sn}$-protoporphyrin (Fig. 1) could, in part, reflect such a phenomenon.

The observed decrease in HO-2 protein in the brain is an unpredicted observation and (Fig. 2) most likely contributes in a major way to the observed decreases in bilirubin production in assay system containing brain microsomes from Sn-protoporphyrin-treated rats. The in vitro experiment (Fig. 4), which was designed to examine whether the metalloporphyrin had somehow compromised the immunochemical properties of brain microsomal HO-2, suggests that both the decrease in protein and loss of its integrity were indeed phenomena that occurred in vivo. It is noteworthy that $\mathrm{Zn}$-protoporphyrin had no detectable effects on heme oxygenase isozymes in the brain, neither at the level of activity nor at the protein level (Figs. 1 and 3). Sn-protoporphyrin has been shown to cross the blood-brain barrier in adult and neonatal rats $(34,35)$. Such information, however, is not available for Zn-protoporphyrin. In the absence of such information, the lack of an effect by $\mathrm{Zn}$-protoporphyrin on brain heme oxygenase may reflect the possibility that the zinc complex may not gain entry into the brain and thus is not capable of interacting with brain heme oxygenase isozymes. Alternatively, the lack of $\mathrm{Zn}$-protoporphyrin-mediated effects on the isozymes may be the reflection of differences in kinetic and biochemical aspects of the interaction of the metalloporphyrin with brain heme oxygenase when compared with those of Sn-protoporphyrin.

The oxidation of heme requires the concerted activity of both heme oxygenase and NADPH-cytochrome P-450 reductase. As shown in Table 1 and Figure 2, Sn-protoporphyrin clearly exerts deleterious effects upon both the activity and the level of the reductase protein in the brain. Because Sn-protoporphyrin has not been previously shown to competitively inhibit the reductase activity, it may be surmised that the observed decrease in NADPH-cytochrome P-450 reductase activity (Table 1) reflects primarily a decrease in the tissue level of the protein (Fig. 2). Interestingly, upon supplementation of the heme oxygenase assay system with the reductase, the relative extent of depression of heme oxygenase activity was lessened but was still highly pronounced (Table 1). Specifically, as shown in Figure 1, when heme oxygenase activity was measured in brain microsomes from rats treated $6 \mathrm{~h}$ with Sn-protoporphyrin in an assay system void of exogenous reductase, the activity was decreased to a mere fraction of the control; when the assay was supplemented with reductase, the activity rose to $24 \%$ of control levels. These observations suggest that the decrease in heme oxygenase activity is due in part to a decrease in the activity of NADPH-cytochrome $\mathrm{P}-450$ reductase. It is noteworthy that the brain is capable of cytochrome P-450-mediated drug metabolism (54) for which the concerted activity of NADPH-cytochrome P-450 reductase is needed. Thus, decreased reductase activity could feasibly alter the capacity of the brain to carry out such biotransformations.

Our examination of transcripts for $\mathrm{HO}-1$ and $\mathrm{HO}-2$ in the brain revealed that the observed decrease in heme oxygenase is not due to alterations in the levels of the mRNA, or, in the case of HO-2, a change in the ratio of the two transcripts (Fig. 5). Therefore, the reported potent photosensitizing activity of Snprotoporphyrin and its ability to generate free oxygen radicals $(16,17,20)$ lead us to suspect that loss of the functional HO-2 and NADPH-cytochrome $\mathrm{P}-450$ reductase protein in the brain may be related to the formation and activity of such free radicals. This may be of particular importance when one considers that low levels of antioxidants, such as glutathione $(55,56)$, in the brain may render this organ somewhat less equipped than others to defend against free radical-mediated injury.

Neonatal jaundice can become of major clinical concern in some instances, and, because the customary modes of treatment (phototherapy, barbiturates, and transfusions) have potential drawbacks, alternative methods have been continuously sought. $\mathrm{Sn}$-protoporphyrin is the only metalloporphyrin that has been used experimentally in humans, including neonates $(10,49)$. The results presented here, including the nonspecific deleterious effects of the complex on endoplasmic reticulum constituents, however, are disconcerting and warrant caution for its therapeutic use. In addition, cytochrome P-450-dependent steroid metabolism in the brain has only recently become actively researched $(57,58)$. In light of the fact that Sn-protoporphyrin has been shown to decrease steroidogenesis in rat adrenals and testes (21), it appears reasonable to predict that steroid metabolism may also undergo alterations in brain of Sn-protoporphyrin-treated neonates. This is particularly alarming when one considers the regulatory role steroids play during development. For these reasons, if metalloporphyrin therapy as a treatment for neonatal jaundice continues to grow, we suggest that $\mathrm{Zn}$-protoporphyrin is the agent of choice.

Acknowledgment. The authors thank Lois Schenk for preparation of this manuscript.

\section{REFERENCES}

1. Tenhunen R, Marver HS, Schmid R 1969 Microsomal heme oxygenase: characterization of the enzyme. J Biol Chem 244:6388-6394

2. Maines MD, Kappas A 1974 Cobalt induction of hepatic heme oxygenase: with evidence that cytochrome P-450 is not essential for this enzyme activity. Proc Natl Acad Sci USA 71:4293-4297

3. Falk JE 1964 General chemistry. In: Porphyrins and Metalloporphyrins: Their General, Physical and Coordination Chemistry, and Laboratory Methods. Elsevier, Amsterdam, pp 1-29

4. Maines MD 1988 Heme oxygenase: function, multiplicity, regulatory mechanisms and clinical applications. FASEB J 2:2557-2568

5. Maines MD, Kappas A 1977 Enzymatic oxidation of cobalt-protoporphyrin IX: observations on the mechanism of heme oxygenase. Biochemistry $16: 419-422$

6. Rotenberg MO, Maines MD 1991 Characterization of a cDNA encoding rabbit brain heme oxygenase-2 and identification of a conserved domain among mammalian heme oxygenase isozymes: possible heme binding site? Arch Biochem Biophys 290:336-344

7. Maines MD 1981 Zinc-protoporphyrin is a selective inhibitor of heme oxygenase activity in the neonatal rat. Biochim Biophys Acta 673:339-350

8. Drummond GS, Kappas A 1981 Prevention of neonatal hyperbilirubinemia by tin protoporphyrin IX, a potent competitive inhibitor of heme oxidation Proc Natl Acad Sci USA 78:6466-6470

9. Berglund L, Angelin B, Hultcrantz R, Einarsson K, Drummond GS, Kappas A 1990 Studies with the haem oxygenase inhibitor Sn-protoporphyrin in patients with primary biliary cirrhosis and idiopathic haemochromatosis Gut 31:899-904

10. Kappas A, Drummond GS, Manola T, Petmezaki S, Valaes T $1988 \mathrm{Sn}$ protoporphyrin use in management of hyperbilirubinemia in term newborns with direct Coombs-positive ABO incompatibility. Pediatrics 81:485-497

11. Anderson CE, Simionatto CS, Drummond GS, Kappas A 1986 Disposition of tin-protoporphyrin and suppression of hyperbilirubinemia in humans. Clin Pharmacol Ther 39:510-517

12. Maines MD, Kappas A 1975 The degradative effects of porphyrins and heme compounds on the components of the microsomal mixed function oxidase. J Biol Chem 250:2363-2369

13. Cannistraro S, Van De Vorst A, Jori G 1978 EPR studies on singlet oxygen production by porphyrins. Photochem Photobiol 28:257-259

14. Lightner DA 1982 Structure, photochemistry, and organic chemistry of bilirubin. In: Heirwegh KPM, Brown SB (eds) Bilirubin, Vol 1. CRC Press, Boca Raton, FL, pp 1-58

15. Aft RL, Muller GC 1984 Hemin-mediated degradation of proteins. J Biol Chem 259:301-305

16. McDonagh AF, Palma LA 1985 Tin-protoporphyrin: a potent photosensitizer of bilirubin obstruction. Photochem Photobiol 42:261-264

17. Land SA, McDonagh AF, McGarvey DJ, Truscott TG 1988 Photophysical structures of tin (IV) protoporphyrin IX dichloride, a novel chemotherapeutic agent for the prevention of neonatal jaundice. Proc Natl Acad Sci USA $85: 5249-5253$

18. Vreman HJ, Stevenson DK 1990 Metalloporphyrin-enhanced photodegradation of bilirubin in vitro. Am J Dis Child 144.590-594

19. Hintz SR, Vreman HJ, Stevenson DK 1990 Mortality of metalloporphyrintreated neonatal rats after light exposure. Dev Pharmacol Ther 14:187-192

20. Mimura S, Nagae H, Keino H, Watanabe S, Kashiwamata S 1991 Sn-protoporphyrin plus photoirradiation induces lipid perioxidation in vivo and in vitro in nonjaundiced Gunn rats. Biol Neonate 60:39-44

21. Trakshel GM, Sluss PM, Maines MD 1992 Comparative effects of tin- and zinc-protoporphyrin on steroidogenesis: tin-protoporphyrin is a potent in- 
hibitor of cytochrome P-450-dependent activities in the rat adrenals. Pediatr Res 31:196-201

22. Maines MD, Trakshel GM, Kutty RK 1986 Characterization of two constitutive forms of rat liver microsomal heme oxygenase: only one molecular species of the enzyme is inducible. J Biol Chem 261:411-419

23. Trakshel GM, Kutty RK, Maines MD 1986 Purification and characterization of the major constitutive form of testicular heme oxygenase: the noninducible isoform. J Biol Chem 261:11131-11137

24. Rotenberg MO, Maines MD 1990 Isolation, characterization, and expression in Escherichia coli of a cDNA encoding rat heme oxygenase-2. J Biol Chem 265:7501-7506

25. Cruse I, Maines MD 1988 Evidence suggesting that the two forms of heme oxygenase are products of different genes. J Biol Chem 263:3348-3353

26. Shibahara S, Müller R, Taguchi H 1987 Transcriptional control of the rat heme oxygenase by heat shock. J Biol Chem 262:12889-12892

27. Keyse SM, Tyrrell RM 1989 Heme oxygenase is the major 32-kDa stress protein induced in human skin fibroblasts by UVA radiation, hydrogen peroxide, and sodium arsenite. Proc Natl Acad Sci USA 86:99-103

28. Ewing JF, Maines MD 1991 Rapid induction of heme oxygenase-1 mRNA and protein by hyperthermia in rat brain: heme oxygenase-2 is not a heat shock protein. Proc Natl Acad Sci USA 88:5364-5368

29. Ewing JF, Haber SN, Maines MD 1992 Normal and heat-induced patterns of expression of heme oxygenase-1 (HSP 32) in rat brain: hyperthermia causes rapid induction of mRNA and protein. J Neurochem 58:1140-1149

30. Shibahara S, Müller R, Taguchi H, Yoshida T 1985 Cloning and expression of a cDNA for rat heme oxygenase. Proc Natl Acad Sci USA 82:7865-7869

31. Trakshel GM, Kutty RK, Maines MD 1988 Resolution of the rat brain heme oxygenase activity: absence of a detectable amount of the inducible form (HO-1). Arch Biochem Biophys 260:732-739

32. Trakshel GM, Maines MD 1989 Multiplicity of heme oxygenase isozymes HO1 and HO-2 are different molecular species in rat and rabbit. J Biol Chem 264:1323-1328

33. Sun Y, Rotenberg MO, Maines MD 1990 Developmental expression of heme oxygenase isozymes in rat brain: two HO-2 mRNAs are detected and HO-1 mRNA is inducible. J Biol Chem 265:8212-8217

34. Anderson KE, Simionatto CS, Drummond GS, Kappas A 1984 Tissue distribution of tin-protoporphyrin, a potent competitive inhibitor of heme oxygenase. J Pharmacol Exp Ther 228:327-333

35. Drummond GS, Kappas A 1986 Sn-protoporphyrin inhibition of fetal and neonatal brain heme oxygenase: transplacental passage of the metalloporphyrin and prenatal suppression of hyperbilirubinemia in the newborn animal. J Clin Invest 77:971-976

36. Maines MD 1980 Regional distribution of the enzymes of haem biosynthesis and the inhibition of $\delta$-aminolevulinate synthetase by manganese in the rat brain. Biochem J 196:285-292

37. Yasukochi Y, Masters BS 1976 Some properties of a detergent-solubilized NADPH-cytochrome c (cytochrome P-450) reductase purified by biospecific affinity chromatography. J Biol Chem 251:5337-5344

38. Kutty RK, Maines MD 1981 Purification and characterization of biliverdin reductase from the rat liver. J Biol Chem 256:3956-3962

39. Trakshel GM, Kutty RK, Maines MD 1986 Cadmium-mediated inhibition of testicular heme oxygenase activity: the role of NADPH-cytochrome $c$ (P450) reductase. Arch Biochem Biophys 251:175-187

40. Rotenberg MO, Chow LT, Broker TR 1989 Characterization of rare human papillomavirus type II mRNAs coding for regulatory and structural proteins by the polymerase chain reaction. Virology 172:489-497

41. Minty AJ, Caravatti M, Robert B, Cohen A, Daubas P, Weydert A, Gros F, Buckingham ME 1981 Mouse actin messenger RNAs. Construction and characterization of a recombinant plasmid molecule containing a complementary DNA transcript of mouse alpha-actin mRNA. J Biol Chem 256:1008-1014

42. Maniatis T, Fritsch EF, Sambrook J 1982 Molecular Cloning: A Laboratory Manual. Cold Spring Harbor Laboratory, Cold Spring Harbor, NY

43. Chirgwin JM, Przybyla AE, MacDonald RJ, Rutter WJ 1979 Isolation of biologically active ribonucleic acid from sources enriched in ribonuclease. Biochemistry 18:5294-5299

44. Kingsteon RE 1987 Preparation of poly(A) ${ }^{+}$RNA. In: Ausubel FM, Brent R, Moore DD, Smith JA, Seidman JG, Struhl K (eds) Current Protocols in Molecular Biology. Wiley, New York, pp 4.5.1-4.5.3

45. Strobel HW, Dignam JD 1978 Purification and properties of NADPH-cytochrome P-450 reductase. Methods Enzymol 53:89-96

46. Lowry OH, Rosebrough NJ, Farr AL, Randall RJ 1951 Protein measurement with the Folin phenol reagent. J Biol Chem 193:265-275

47. Laemmli UK 1970 Cleavage of structural proteins during the assembly of the head of bacteriophage T4. Nature 227:680-685

48. Towbin H, Staehelin T, Gordon J 1979 Electrophoretic transfer of proteins from polyacrylamide gels to nitrocellulose sheets: procedure and some applications. Proc Natl Acad Sci USA 76:4350-4354

49. Sardana MK, Kappas A 1987 Dual control mechanism for heme oxygenase: tin(IV)-protoporphyrin potently inhibits enzyme activity while markedly increasing content of enzyme protein in liver. Proc Natl Acad Sci USA 84:2464-2468

50. Kappas A, Drummond GS 1985 Synthetic metalloporphyrins: a class of compounds of pharmacological interest. Bioessays 3:256-259

51. Sassa S, Drummond GS, Bernstein SE, Kappas A 1985 Long-term administration of massive doses of Sn-protoporphyrin in anemic mutant mice (sphha/ sphha). J Exp Med 162:864-876

52. Drummond GS, Rosenberg DW, Kihlstrom-Johanson AC, Kappas A 1989 Effect of tin-porphyrins on developmental changes in hepatic cytochrome P450 content, selected P450-dependent drug-metabolizing enzyme activities, and brain glutathione levels in the newborn rat. Pharmacology 39:273-284

53. McCoubrey $\mathrm{Jr}_{\mathrm{r}} \mathrm{WK}$, Ewing JF, Maines MD 1992 Characterization and expression of a full length human heme oxygenase- $2 \mathrm{cDNA}$ and evidence suggesting the two HO-2 transcripts differ by choice of polyadenylation signal. Arch Biochem Biophys 295:13-20

54. Liccione JJ, Maines MD 1989 Manganese-mediated increase in the rat brain mitochondrial cytochrome P-450 and drug metabolism activity: susceptibility of the striatum. J Pharmacol Exp Ther 248:222-228

55. Raps SP, Lai J, Herts L, Cooper AJL 1989 Glutathione is present in high concentrations in cultured astrocytes but not in cultured neurons. Brain Res 493:398-401

56. Slivka A, Mytilineou C, Cohen G 1987 Histochemical evaluation of glutathione in brain. Brain Res 409:275-284

57. Walther B, Ghersi-Egea J, Minn A, Siest G 1987 Brain mitochondrial cytochrome P-450 sc: spectral and catalytic properties. Arch Biochem Biophys 254:592-596

58. Le Goascogne C, Robel P, Gouezou M, Sananes N, Baulieu E, Waterman M 1987 Neurosteroids: cytochrome P.450 1215 